\title{
Characteristics of Symptomatic Reflux Episodes in Patients with Non-Erosive Reflux Disease Who Have a Positive Symptom Index on Proton Pump Inhibitor Therapy
}

\author{
Katsuhiko Iwakiri ${ }^{a}$ Hirohito Sano $^{a}$ Yuriko Tanaka ${ }^{a}$ Noriyuki Kawami ${ }^{a}$ \\ Mariko Umezawa $^{a}$ Seiji Futagami ${ }^{a}$ Yoshio Hoshihara ${ }^{a, c}$ Tsutomu Nomura ${ }^{b}$ \\ Masao Miyashita $^{\mathrm{b}}$ Choitsu Sakamoto $^{\mathrm{a}}$ \\ a Division of Gastroenterology, Department of Medicine, and ' ${ }^{b}$ Department of Surgery, Nippon Medical School, Tokyo, \\ ${ }^{c} \mathrm{Clinic}$ of the Ministry of Economy, Trade and Industry, Japan
}

\section{Key Words}

Symptomatic reflux episodes $\cdot$ Persistent heartburn •

Proximal reflux $\cdot$ Non-erosive reflux disease .

Impedance-pH monitoring

\begin{abstract}
Background and Aim: The reason that some reflux episodes evoke symptoms is poorly understood, therefore the aim of this study is to assess the determinants of reflux perception in patients with non-erosive reflux disease (NERD) on proton pump inhibitor (PPI) therapy. Methods: Ten NERD patients with persistent symptoms, despite double-dose PPI therapy, were included in this study. All patients had a positive symptom index (SI), which was determined by ambulatory 24hour combined impedance-pH monitoring. Reflux episodes were identified and classified as acid, weakly acidic or weakly alkaline reflux and were considered symptomatic if patients recorded a symptom within 5 min after a reflux episode. Results: A total of 954 liquid reflux episodes were detected, including 135 (14.2\%) acid, 782 (82.0\%) weakly acidic, and 37 (3.9\%) weakly alkaline. Overall, 59 (6.2\%) reflux episodes were symptomatic and the majority (88.1\%) of symptomatic reflux episodes were weakly acidic reflux. When re-
\end{abstract}

flux episodes were confined to the distal esophagus, there were very few reflux symptoms. Proximal reflux is significantly more likely to be associated with reflux symptoms, irrespective of the acidity of the refluxate or the duration of proximal reflux episodes. Conclusions: In NERD patients who have a positive SI on double-dose PPI therapy, the high proximal extent of refluxate is a major factor associated with reflux perception.

Copyright $\odot 2010$ S. Karger AG, Basel

\section{Introduction}

Multiple intraluminal impedance (MII)-monitoring has recently been introduced as being a new and reproducible technique for monitoring gastroesophageal reflux $[1,2]$. This technique detects reflux episodes, independently of the $\mathrm{pH}$ of the refluxate, which also allows identification of non-acid reflux. Combined MII-pH monitoring allows detection of all reflux events, regardless of acidity (acid/non-acid) and composition (liquid/ gas/mixed) [1]. It has recently been shown that combined MII-pH monitoring is more accurate for the detection of both acid and non-acid reflux than $\mathrm{pH}$ alone $[3,4]$ and 
some reflux episodes can be associated with reflux symptoms. It is poorly understood, however, why some reflux episodes evoke symptoms and others do not. In patients off therapy, reflux symptoms are more likely to be evoked (i) when $\mathrm{pH}$ drop is high [5], (ii) when the nadir $\mathrm{pH}$ is low [5], (iii) when high proximal extent occurs $[5,6]$, or (iv) when bolus (volume) or acid clearance $[5,6]$ is delayed. In contrast, in patients on therapy, it has been reported that the high proximal extent of refluxate is an important factor associated with reflux perception $[7,8]$. There are, however, very few reports regarding the relationship between reflux symptoms and reflux episodes on proton pump inhibitor (PPI) therapy. Bolus clearance time (BCT) has usually been evaluated at $5 \mathrm{~cm}$ above the proximal margin of the lower esophageal sphincter (LES) [5, $7,8]$. In our previous study [9], however, we noticed that reflux-related symptoms at $5 \mathrm{~cm}$ above the proximal margin of the LES were very rare. The relationship between $\mathrm{BCT}$ in symptomatic and asymptomatic proximal reflux episodes, where refluxate reaches 15 or $17 \mathrm{~cm}$ above the proximal margin of the LES, the point at which reflux symptoms are more likely to be symptomatic, should therefore be investigated. In addition, the proportion of symptomatic reflux episodes, on PPI therapy at each impedance site, is still unclear. Furthermore, few reports have been carried out as to the relationship between the $\mathrm{pH}$ of refluxate and symptomatic reflux episodes. The aim of this study is to investigate the characteristics of symptomatic reflux episodes in non-erosive reflux disease (NERD) patients with a positive symptom index (SI), despite taking on double-dose PPI.

\section{Methods}

\section{Patients}

Simultaneous 24-hour ambulatory combined MII-pH monitoring was carried out on 18 consecutive NERD patients ( 7 male and 11 female, mean age 50.8 years, range $32-79)$. These patients all had a typical reflux symptom (heartburn), which occurred more than twice per week, despite taking rabeprazole $10 \mathrm{mg}$ twice daily for at least 8 weeks prior to testing in the Nippon Medical School Hospital between December 2006 and August 2009. Patients were considered to have had NERD when no esophageal mucosal injury was found during an upper gastrointestinal endoscopy, prior to medication and also when no esophageal motility disorder was found during high-resolution manometry.

Only patients with a positive SI ( $\geq 50 \%)$ for liquid reflux episodes were selected for further analysis and 8 patients were excluded for having negative symptom-reflux association. In total, 10 patients ( 4 male and 6 female, mean age 49.6 years, range 3671) were finally included in this study. Exclusion criteria were any previous esophageal or gastric surgery. Informed consent was obtained from all subjects, and the study was conducted according to the provisions of the Declaration of the Helsinki.

\section{Combined MII-pH Monitoring}

The study was carried out on an outpatient basis, after at least $6 \mathrm{~h}$ of fasting. A combined MII-pH probe was placed in reference to the manometrically-located proximal border of the LES, using high-resolution manometry. When the manometry had been completed, a 2.1-mm MII-pH probe was passed transnasally and the esophageal $\mathrm{pH}$ probe was positioned $5 \mathrm{~cm}$ above the proximal margin of the LES. The configuration of the catheter allowed monitoring changes in intraluminal impedance at 3, 5, 7, 9, 15 and $17 \mathrm{~cm}$ above the proximal margin of the LES. In addition, $\mathrm{pH}$ was monitored at $5 \mathrm{~cm}$ above and $10 \mathrm{~cm}$ below the proximal margin of the LES.

Patients then underwent 24-hour MII-pH monitoring and diaries were provided for them to record their symptoms during the study period. Patients were encouraged to maintain normal activity, sleep schedules and usual meals at regular times. Data from the impedance channels and the $\mathrm{pH}$ electrodes were sampled at a frequency of $50 \mathrm{~Hz}$ and stored on a portable data recorder (Sleuth; Sandhill Scientific, Inc., Highlands Ranch, Colo., USA). At the end of the 24-hour recording period, data were transferred and analyzed manually, using dedicated software (BioView ${ }^{\circledR}$ analysis; Sandhill Scientific, Inc.).

\section{Data Analysis}

Tracings were reviewed, meal periods were timed, changes in body position were noted and the time at which symptoms were recorded was compared with the information written in the diaries. Meal periods were marked and excluded from the analysis. Liquid reflux episodes (liquid only and mixed gas-liquid) were identified, by previously described criteria, as a retrograde $50 \%$ decline in impedance from baseline, in at least two sites. Gas-only reflux episodes (simultaneous increase in impedance $>3,000 \Omega$ in any two consecutive sites, with one site having an absolute value $>7,000 \Omega$ ) were not included in the analysis.

Reflux episodes were characterized by $\mathrm{pH}$ measurement as acid, weakly acidic or weakly alkaline according to a recently published consensus report on detection and definitions of gastroesophageal reflux; (i) acid reflux: refluxed gastric juice with a $\mathrm{pH}<4$, which can either reduce the $\mathrm{pH}$ of the esophagus to $<4$ or occur when the esophagus $\mathrm{pH}$ is already $<4$; (ii) weakly acidic reflux: reflux events that result in an esophageal pH between 4 and 7 , and (iii) weakly alkaline reflux: reflux episodes during which nadir esophageal $\mathrm{pH}$ does not drop below 7 [1].

Combined MII-pH data allowed for separation of symptoms into those associated with acid reflux, weakly acidic reflux, weakly alkaline reflux, or not associated with reflux. A symptom was considered to be associated with reflux if a reflux episode was detected 5 min prior to the symptom occurring. The SI was calculated for each patient in relation to liquid reflux and was defined as the number of symptoms associated with reflux, divided by the total number of symptoms [10]. A positive SI was detected if more than $50 \%$ (that is, at least half of the symptoms were associated with reflux). Patients were considered to have had an overall positive SI if at least one symptom of the following (heartburn, chest pain or dysphagia) was positive. 
Table 1. Demographic characteristics (age, gender) and individual results of a symptom index for all symptoms, each symptom, acid reflux, weakly acidic reflux and weakly alkaline reflux of 10 patients who had a positive symptom index

\begin{tabular}{|c|c|c|c|c|c|c|c|c|}
\hline & \multirow[t]{2}{*}{ Age } & \multirow[t]{2}{*}{ Gender } & \multirow[t]{2}{*}{ Symptom } & \multicolumn{5}{|c|}{ Symptom index for } \\
\hline & & & & $\begin{array}{l}\text { all } \\
\text { symptoms, \% }\end{array}$ & $\begin{array}{l}\text { each } \\
\text { symptom, \% }\end{array}$ & $\begin{array}{l}\text { acid } \\
\text { reflux, \% }\end{array}$ & $\begin{array}{l}\text { weakly acidic } \\
\text { reflux, \% }\end{array}$ & $\begin{array}{l}\text { weakly alkaline } \\
\text { reflux, \% }\end{array}$ \\
\hline 1 & 64 & female & $\begin{array}{l}\text { heartburn } \\
\text { dysphagia }\end{array}$ & 83.3 & $\begin{array}{r}75 \\
100\end{array}$ & 66.7 & 16.7 & 0 \\
\hline 2 & 71 & male & $\begin{array}{l}\text { heartburn } \\
\text { dysphagia }\end{array}$ & 50 & $\begin{array}{l}57.1 \\
33.3 \\
\end{array}$ & 0 & 50 & 0 \\
\hline 3 & 67 & male & heartburn & 100 & 100 & 0 & 100 & 0 \\
\hline 4 & 42 & male & heartburn & 62.5 & 62.5 & 0 & 62.5 & 0 \\
\hline 5 & 38 & female & heartburn & 100 & 100 & 100 & 0 & 0 \\
\hline 6 & 39 & female & heartburn & 69.2 & 69.2 & 0 & 69.2 & 0 \\
\hline 7 & 43 & female & $\begin{array}{l}\text { heartburn } \\
\text { dysphagia } \\
\text { chest pain }\end{array}$ & 51.8 & $\begin{array}{c}57.1 \\
50 \\
0\end{array}$ & 0 & 51.9 & 0 \\
\hline 8 & 36 & female & heartburn & 62.5 & 62.5 & 0 & 62.5 & 0 \\
\hline 9 & 45 & female & heartburn & 50 & 50 & 50 & 0 & 0 \\
\hline 10 & 51 & male & heartburn & 100 & 100 & 25 & 75 & 0 \\
\hline
\end{tabular}

BCT of refluxate was defined as the time, in seconds, from the $50 \%$ drop in impedance until impedance again recovered to above this point. When refluxate reached 15 or $17 \mathrm{~cm}$ above the proximal margin of the LES, the BCT was calculated from where refluxate reached the highest point and proximal reflux was defined as a reflux episode where refluxate reached 15 or $17 \mathrm{~cm}$ above the LES.

\section{Statistical Analysis}

Analysis was performed using pooled data and comparisons of proportions were calculated using the $\chi^{2}$ test. Comparisons between the BCT of symptomatic and asymptomatic reflux episodes were performed using the Mann-Whitney test. Significance was established at a $\mathrm{p}$ value of $<0.05$.

\section{Results}

Ten (55.6\%) of a total of 18 patients had a positive SI. Three patients (16.6\%) had a positive SI for acid reflux and 7 patients (38.9\%) had a positive SI for weakly acidic reflux. Ten patients with a positive SI recorded between one and three types of symptom (e.g. heartburn, chest pain, dysphagia) during the study: 7 patients recorded one type of symptom, the remaining 3 patients recorded two or three different types of symptom. Table 1 shows demographic characteristics and individual results of a SI for all symptoms, each symptom, acid reflux, weakly acidic reflux and weakly alkaline reflux of 10 patients who had a positive SI. None of the patients had hiatus hernia, de- fined as when the LES-crural diaphragm separation is $>2 \mathrm{~cm}$ at inspiration, using high-resolution manometry.

\section{Reflux Episodes on PPI Therapy}

In the 10 patients with a positive SI, 954 liquid-containing reflux episodes were recorded. Amongst these, 135 (14.2\%) were acid reflux, 782 (82.0\%) were weakly acidic reflux and 37 (3.9\%) were weakly alkaline reflux.

\section{Reflux-Related Symptoms on PPI Therapy}

A total of 93 symptoms was recorded by patients during the study, 59 (63.4\%) of which were related to reflux episodes and 59 (6.2\%) of the total 954 reflux episodes were accompanied by reflux symptoms. Seven (7.5\%) of the 93 symptoms were related to acid reflux, 52 (55.9\%) were related to weakly acidic reflux and the cause of the remaining 34 symptoms (36.6\%) was unknown (fig. 1). There was no weakly alkaline reflux associated with reflux symptoms, therefore the majority (93.8\%) of reflux episodes on double-dose PPI therapy were asymptomatic and the majority (88.1\%) of symptomatic reflux episodes were associated with weakly acidic reflux.

\section{Proportion of Symptomatic Reflux Episodes for Each Mechanism of Reflux Episodes}

Seven (5.2\%) of 135 acid reflux episodes and 52 (6.6\%) of 782 weakly acidic reflux episodes were symptomatic but no weakly alkaline reflux episodes were associated 


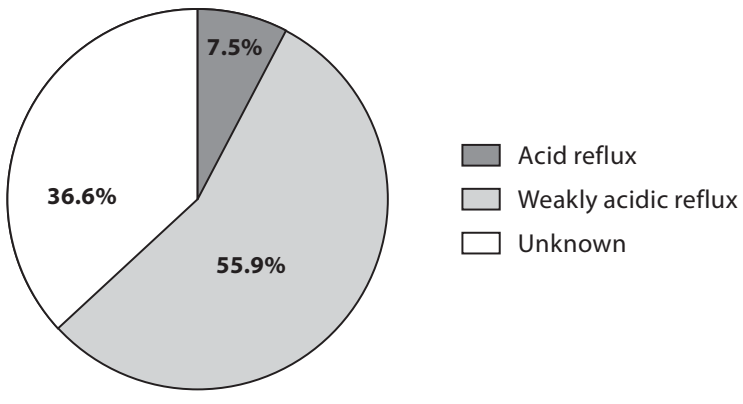

Fig. 1. Mechanisms of persistent symptoms in patients with NERD with a positive SI on double-dose PPI therapy.

with reflux symptoms. There was no difference in the proportion of symptomatic reflux episodes for each mechanism of a reflux episodes, therefore reflux symptoms are evoked, irrespective of whether $\mathrm{pH}$ is acidic $(<4.0)$, weakly acidic $(4-7)$, or weakly alkaline $(\geq 7.0)$.

\section{Proportion of Symptomatic Reflux Episodes at Each Impedance Site}

The proportion of symptomatic reflux episodes at 5, 7, 9, 15 and $17 \mathrm{~cm}$ above the proximal margin of the LES were $1.4 \%$ (2/147), $0.9 \%$ (2/223), $4.0 \%$ (10/249), $13.2 \%$ $(12 / 91)$ and $13.1 \%$ (32/244), respectively (fig. 2). Proximal reflux episodes, where refluxate reaches 15 or $17 \mathrm{~cm}$ above the proximal margin of the LES, is therefore significantly ( $p<0.0001)$ more likely to be associated with symptoms compared with reflux episodes at other sites.

\section{BCT of Symptomatic and Asymptomatic Reflux \\ Episodes}

There was no difference in BCT between symptomatic (12.7 s (4.1-20.2), median (interquartile range)) or asymptomatic (8.2 s (2.6-18.3)) reflux episodes in proximal reflux episode (fig. 3).

\section{Discussion}

All patients took a double-dose of PPI (rabeprazole 10 mg twice daily), to, as far as possible, rule out the possibility that persistent symptoms in patients with NERD is

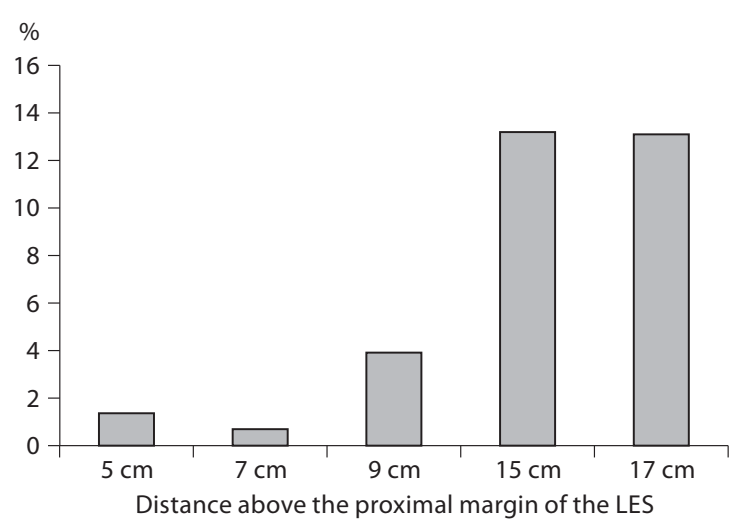

Fig. 2. Proportion of symptomatic reflux episodes at each impedance site. Proximal reflux episodes, where refluxate reaches 15 or $17 \mathrm{~cm}$ above the proximal margin of the LES, is significantly $(\mathrm{p}<$ 0.0001) more likely to be associated with symptoms.

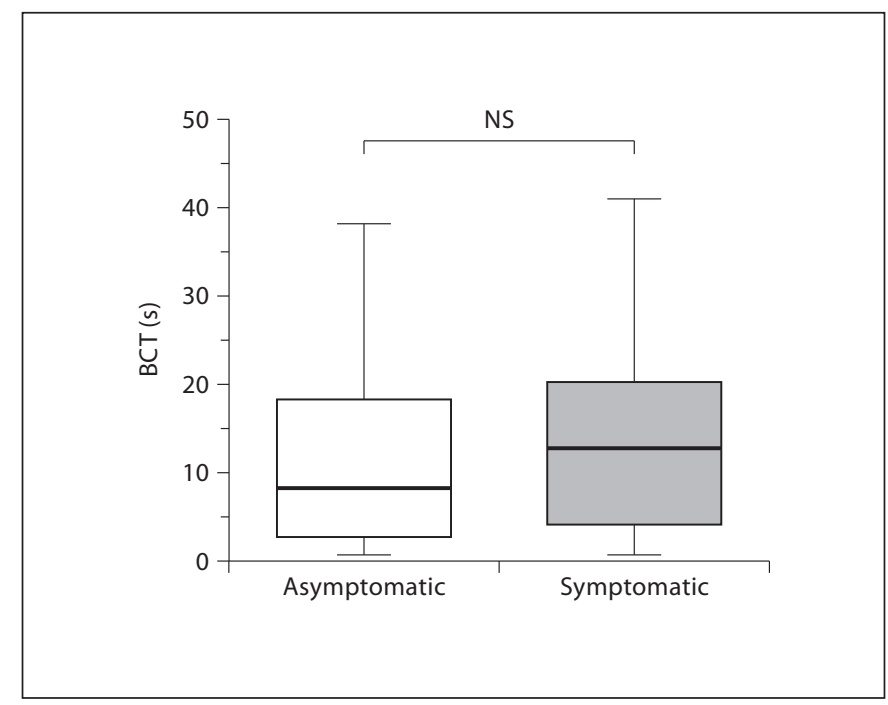

Fig. 3. BCT of symptomatic and asymptomatic reflux episodes, where refluxate reaches 15 or $17 \mathrm{~cm}$ above the proximal margin of the LES. NS = Not significant.

unrelated to acid reflux. In Western countries, $20 \mathrm{mg}$ of rabeprazole is the standard dose for reflux esophagitis (RE) but, in Japan, $20 \mathrm{mg}$ of rabeprazole is considered to be double-dose PPI therapy for RE.

Combined MII-pH monitoring in the 10 patients, with a positive SI, showed that reflux-related symptoms occurred in $6.2 \%$ of reflux episodes and $63.4 \%$ of reflux symptoms were related to reflux episodes (acid reflux/ 
weakly acidic reflux). 7.5\% were related to acid reflux and $55.9 \%$ were related to weakly acidic reflux. There were no symptoms related to weakly alkaline reflux, therefore in patients with NERD, with a positive SI, on double-dose PPI therapy, weakly acidic reflux is the major mechanism which underlies persistent symptoms.

The mechanism of the determinants of the perception of reflux episodes is still unclear. In previous reports when off therapy, it has been reported that symptomatic reflux episodes in gastroesophageal reflux disease (GERD) patients were of longer distal reflux duration and reached a higher proximal extent than asymptomatic reflux episodes [5, 6]. In another report, in patients with NERD and $\mathrm{RE}$, proximal reflux episodes were perceived as being more than distal reflux episodes, independent of reflux duration and that patients with NERD were significantly more sensitive to proximal reflux episodes than those with RE [11]. Therefore, proximal reflux episodes and longer distal reflux duration are considered to be important factors of the perception of reflux when off therapy.

There are very few reports about the determinants of the perception of reflux when on PPI therapy, however in previous reports it has been reported that the proximal extent of refluxate is an important factor in the perception of reflux $[7,8]$. The present study has also shown that reflux episodes, where refluxate reaches the proximal esophagus, were significantly more likely to be perceived as symptoms than reflux episodes, which are confined to the distal esophagus. In addition, we have shown the proportion of symptomatic reflux episodes at each impedance site and that reflux episodes, where refluxate reaches 5 and $7 \mathrm{~cm}$ above the proximal margin of the LES, have very few reflux symptoms (0.9-1.4\%). Although, in most studies, reflux duration has been evaluated at the distal esophagus ( $5 \mathrm{~cm}$ above the proximal margin of the LES), when considering the proportion of symptomatic reflux episodes at $5 \mathrm{~cm}$ above the proximal margin of the LES, we believe that the relationship between reflux duration and symptomatic reflux episodes should be evaluated using proximal reflux episodes, which are more likely to be symptomatic. In our study, there was no difference in the $\mathrm{BCT}$ of proximal reflux between symptomatic and asymptomatic reflux episodes.

There is no difference, with regard to the proportion of symptomatic reflux episodes, in acid reflux and weakly acidic reflux. This result suggests therefore that reflux episodes extending proximally are a major important factor in the perception of reflux irrespective of whether the $\mathrm{pH}$ is acidic $(<4.0)$, weakly acidic $(4-7)$, or weakly alkaline $(\geq 7.0)$, and the duration of proximal reflux epi- sodes. However, the proportion of symptomatic reflux episodes to reflux episodes is approximately $13 \%$, therefore it is thought that there is another large, unknown factor related to reflux symptoms.

Esophageal hypersensitivity is considered to be one of the factors of symptomatic reflux episodes in patients with NERD [10-12]. Considering that the high proximal extent of refluxate is the only important factor associated with the perception of reflux, esophageal hypersensitivity in patients with NERD is present in the proximal esophagus, not the entire esophagus.

The mechanism of proximal reflux remains poorly understood. One possible explanation is an increased reflux volume, which causes esophageal distention [13], however it is not possible to measure the volume of refluxate. Another reason might be a defective triggering of secondary peristalsis in patients with NERD [14]. However, whether or not defective secondary peristalsis contributes to reflux symptoms remains to be determined. It is likely that refluxate will more readily extend to the upper area of the esophagus if secondary peristalsis does not occur immediately after reflux episodes.

In conclusion, there is a remote possibility (approximately 1.0\%) that reflux episodes, which are confined to the distal esophagus, will have reflux symptoms. The proximal extent of refluxate is an important factor as a determinant of the perception of reflux in NERD patients with persistent symptoms on PPI therapy, irrespective of the acidity of the refluxate and the duration of proximal reflux episodes.

\section{Disclosure Statement}

The authors declare that no financial or other conflict of interest exists in relation to the content of the article.

References

Iwakiri et al.
1 Sifrim D, Castell D, Dent J, Kahrilas PJ: Gastro-oesophageal reflux monitoring: review and consensus report on detection and definitions of acid, non-acid, and gas reflux. Gut 2004;53:1024-1031.

-2 Bredenoord AJ, Weusten BL, Timmer R, Smout AJ: Reproducibility of multichannel intraluminal electrical impedance monitoring of gastroesophageal reflux. Am J Gastroenterol 2005; 100:265-269.

-3 Tutuian R, Vela MF, Shay SS, Castell DO Multichannel intraluminal impedance in esophageal function testing and gastroesophageal reflux monitoring. J Clin Gastroenterol 2003;37:206-215. 
-4 Shay S, Tutuian R, Sifrim D, Vela M, Wise J, Balaji N, Zhang X, Adhami T, Murray J, Peter J, Castell DO: Twenty-four hour ambulatory simultaneous impedance and $\mathrm{pH}$ monitoring: a multicenter report of normal values from 60 healthy volunteers. Am J Gastroenterol 2004;99:1037-1043.

$\checkmark 5$ Bredenoord AJ, Weusten BLAM, Curvers WL, Timmer R, Smout AJPM: Determinants of perception of heartburn and regurgitation. Gut 2006;55:313-318.

6 Weusten BL, Akkermans LM, van BergeHenegouwen GP, Smout AJ: Symptom perception in gastroesophageal reflux disease is dependent on spatiotemporal reflux characteristics. Gastroenterology 1995; 108: 1739-1744.

7 Zerbib F, Duriez A, Roman S, Capdepont M, Mion F: Determinants of gastro-oesophageal reflux perception in patients with persistent symptoms despite proton pump inhibitors. Gut 2008;57:156-160.
8 Tutuian R, MF Vela, Hill EG, Mainie I, Agrawal A, Castell DO: Characteristics of symptomatic reflux episodes on acid suppressive therapy. Am J Gastroenterol 2008; 103:1090-1096.

9 Iwakiri K, Kawami N, Sano H, Tanaka Y, Umezawa M, Kotoyori M, Hoshihara Y, Sakamoto C: Acid and non-acid reflux in Japanese patients with non-erosive reflux disease with persistently reflux symptoms, despite taking a double-dose of proton pump inhibitor: a study using combined $\mathrm{pH}$-impedance monitoring. J Gastroenterol 2009; 44:708-712.

10 Wiener GJ, Richter JE, Copper JB, Wu WC, Castell DO: The symptom index: a clinically important parameter of ambulatory 24 -hour esophageal pH monitoring. Am J Gastroenterol 1988;83:358-361.

11 Cicala M, Emerenziani S, Caviglia R, Guarino MPL, Vavassori P, Ribolsi M, Carotti S, Petitti T, Pallone F: Intra-oesophageal distribution and perception of acid reflux in patients with non-erosive gastro-oesophageal reflux disease. Alimernt Pharmacol Ther 2003;18:605-613.
2 Miwa H, Minoo T, Hojo M, Yaginuma R, Nagahara A, Kawabe M, Ohkawa A, Asaoka D, Kurosawa A, Ohkusa T, Sato N: Oesophageal hypersensitivity in Japanese patients with non-erosive gastro-oesophageal reflux disease. Aliment Pharmacol Ther 2004;20(suppl 1):112-117.

13 EmerenzianiS, Ribolsi M, Sifrim D, Blondeau K, Cicala M: Regional oesophageal sensitivity to acid and weakly acidic reflux in patients with non-erosive reflux disease. Neurogastroenterol Motil 2009;21:253-258.

14 Sifrim D, Mittal R, Fass R, Smout A, Castell D, Tack J, Gregersen H: Acidity and volume of the refluxate in the genesis of gastro-oesophageal reflux disease symptoms. Aliment Pharmacol Ther 2007;25:1003-1015.

15 Iwakiri K, Hayashi Y, Kotoyori M, Tanaka Y, Kawami N, Sano H, Takubo K, Sakamoto C, Holloway RH: Defective triggering of secondary peristalsis in patients with non-erosive reflux disease. J Gastroenterol Hepatol 2007;22:2208-2211. 